\title{
USING ROLE-PLAYING GAME FOR PROFESSIONAL SKILLS FORMATION OF PROSPECTIVE TEACHERS
}

\author{
Svitlana Ivanova \\ South Ukrainian National Pedagogical University named after K. D. Ushynsky, Ukraine
}

Lubomir Dimitrov

Technical University of Sofia, Bulgaria

Viktor Ivanov

Odessa National Polytechnic University, Ukraine

Lada Prokopovych

Odessa National Polytechnic University, Ukraine

\begin{abstract}
The features of using Role-playing games in educating students - prospective teachers are considered. In practical classes on teaching methods of various disciplines, Role-playing games are often used, associated with conducting a fragment of a lesson or a full lesson. Typically, these practical classes are organized on an empirical level. The version of the Roleplaying game "Observing Mathematics Lessons", developed on the basis of the theory of contextual learning, is presented. Psychological and pedagogical principles: simulation of specific conditions, game modelling of the content and forms of professional activity, collaborative activities are used in the design of the game. These principles are the basis for creating a game model, which consists of: game goals, a set of roles that indicate the functions of the player, the scenario and the rules of the game. The simulation model contains: didactic goals, the subject of the game and the evaluation system. An important difference developed by the Role-playing game is to take into account the personality types of students - participants in the game. Students with personality types typical for STEM students were selected for the role of "good pupil". The roles of the "bad pupils" were played by students with personality types typical for students who usually do not have academic success in mathematics. A survey has been conducted, which showed that the proposed Role-playing game enable the simulation of the real situation of an observing mathematics lesson.
\end{abstract}

Keywords: observing mathematics lessons, personality types, role-playing games.

\section{Introduction}

The business game is widely used to train prospective managers (Fito-Bertran, Hernandez-Lara, \& Serradell-Lopez, 2014). The idea of this method is to simulate situations that arise in real life in the educational process (Lui \& Au, 2020). In pedagogy, the more commonly used term is role-playing game. This term has a broader interpretation. In the phrase "role-playing game", 
some researchers put the word "game" in the first place (Shafie \& Fatimah, 2011). Role-playing game is understood as teaching methods based on the creation of game situations or increasing the interest of students through the presentation of material in the form of a game. With this approach, the use of computer games is a role-playing game (Ahmad, Shafie \& Latif, 2010). It is suggested to use Math Quest for teaching primary schools pupils. The use of the arcade genre has been known for a long time. The use of computer graphics increases interest in the game, but do not change its essence. To a certain extent, computer graphics can entertain the pupils and distract him from studying mathematics. Massive Multiplayer games are even more popular with children, but even more distracting from the Math. In the study (Anagnostopoulou \& Olivotos, 2019) note that Massive Multiplayer games are - "such that players are enjoying first and learning simultaneously". Another use of games in learning mathematics is playing with school objects. This is the use of well-known counting sticks and various other objects (Kilgour, Reynaud, Northcote, \& Shields, 2015). Games of this type are effective in teaching primary school pupils. The use of games with school objects and arcade games in high school is impractical and even less suitable for teaching university students. To prepare prospective teachers, it was proposed to use the program Second Life. This program allows you to create a variety of content that simulate the real world or fictional reality. Using the capabilities provided by the program, situations in the lesson are simulated (Mahon, Bryant, Brown \& Kim, 2010). Each student can be assigned an avatar. This computer character is endowed with certain characteristics that emphasize his personality (Ma et al., 2016). It is noted that role-playing games are important for modelling relationships in society (Jarvis, Odell, \& Troiano, 2002). Examples of the use of this teaching method for projecting historical realities on students or getting them into the image of a representative of another race are given. The full benefits of role-playing game can be realized when simulating situations by students, and not by computer characters. The tournament of young physicists simulates the interaction of researchers in solving a scientific problem (Vanovskiy, 2014). The situation of the scientific report is also modelled. The speaker from one team is opposed by an opponent from the other team, there is also a reviewer - this is a representative of the third team. A specific set of positions that engineers can work in is presented in the role-playing game - Formula Student (Chryssolouris, Mourtzis, Stavropoulos, Mavrikios, \& Pandremenos, 2008). This version of the game is closest to the business one. It was noted that pupils should be selected into teams taking into account their personality characteristics (Crow \& Nelson, 2015). The selection of team members can be done based on Belbin's team roles. To model the personal characteristics of students, it is preferable to use the personality types of Myers Briggs (Ivanova, Dimitrov, Ivanov \& Naleva, 2019). 


\section{Methodology of Role-playing Game}

At training prospective teachers role-playing game associated with conducting a fragment of a lesson or a full lesson is often used. Such game is used in practical classes on methods of teaching various disciplines. However, these games are often organized on an empirical level, without the use of modern theoretical developments in role-playing games.

For students - prospective teachers of mathematics, a role-playing game "Observing Mathematics Lessons" was developed based on the theory of contextual learning. This theory is proposed by John Dewey (Dewey, 1927) and developed other researchers: (Johnson, 2002; Verbickij \& Larionova, 2009; Schmidt, 2010). The authors of this theory assume that the education of students at the university should be as close as possible to their future professional activity. Therefore, it is important to model the substantive and social content of this activity by creating real professional situations, for example, when conducting role-playing games.

When designing the game "Observing Mathematics Lessons", the psychological and pedagogical principles of the theory of contextual learning were used:

- $\quad$ simulation of specific conditions;

- $\quad$ game modelling of the content and forms of professional activity;

- joint activities;

- dialogical communication;

- $\quad$ principle of two-dimensional;

- formulation of problems related to the content of the simulation model, and discussion of possible options for their solution in the process of game activity.

The first two principles are inseparable, since the modelling of specific conditions is the modelling of professional activity, which is carried out in the form of games. The principle of joint activity provides that a group of students participate in a role-playing game. For the presented version of the game "Observing Mathematics Lessons" the minimum number of participants is 7-8 people. It is substantiated that with a smaller number of participants, no opportunities are created to imitate the specific conditions of professional activity, that is, the second principle is violated. The principle of dialogical communication acts as a necessary condition for achieving learning goals in a specific lesson or part of a lesson. The implementation of this principle is provided by the role positions of the participants. Each participant must analyze problematic situations that arise during the game and act in accordance with the chosen role. The principle of two-dimensionality provides that the achievement of game goals is at the same time a means of forming a teacher's professional skills. The conditional 
goal of the game is to get the maximum number of points for participating in it. The real goal is to form the professional skills of prospective teachers. The implementation of this principle is closely related to the motivation of the participants in the game. The implementation of the principle of setting the task related to the content of the simulation model, and the discussion of possible options for solving them in the process of playing activities occurs when development a role-playing game.

For the game "Observing Mathematics Lessons" it is necessary to highlight the possible typical problems that a teacher encounters in preparing and conducting a lesson. Game and simulation models were created. The game model consists of game goals, a set of roles indicating the functions of the players, the scenario and the rules of the game. The simulation includes: didactic goals, the subject of the game and the assessment system.

The main game goal of the participant is to fulfil the tasks defined by his role as accurately as possible and to gain the greatest number of points or encouraging comments (depending on the role).

The set of roles includes:

- A "teacher" who, preparing for a lesson, specifies the purpose and type of lesson, develops methods, techniques and means to achieve this goal, and then conducts this lesson;

- "Good pupil" - pupil with a high level of mathematical training, who takes an active part in the lesson, gives the correct answers to the teacher's questions and correctly solves the mathematical problem;

- "Bad pupil" - pupil with a low level of mathematical training, who does not want to take part in the lesson, is often distracted, makes mistakes when solving exercises;

- The "principal" is the one who checks the "teacher".

In the scenario of the game, the main stages were described: introduction to the game (at this stage the participants were told the rules of the game, the topic of the lesson were determined, the roles were assigned); preparation for the game; playing the game; analyzing the game. The didactic goal of the game is the formation of the prospective teacher's professional skills (lesson planning, organization and management of the pupil's activities in the lesson, assessment of their activities in the lesson, etc.). The subject of the game is the process of preparing, conducting and methodological analysis of the lesson.

\section{The hypothesis of the study.}

The following statement is accepted as hypotheses of a study:

- $\mathrm{H}_{\mathrm{a}}$ - Taking into account the personality types of the participants in the role-playing game "Observing Mathematics Lessons" allowed to better model the real situation in the lessons. 
- $H_{b}$ - Taking into account the personality types of the participants in the role-playing game "Observing Mathematics Lessons" allowed to better develop professional skills.

\section{Tools are used to test these hypotheses of a study.}

- $\quad$ The Keirsey Temperament Sorter. Student's personality types were determined using the Keirsey questionnaire. The first test was conducted six months before the experiment. The second test was performed immediately before the role-playing game. The coincidence of the results of the first and second tests was in the range of 78-82\%, which is within the acceptable range (75-90\%) in accordance with (Capraro, R. \& Capraro, M., 2002).

- $\quad$ The expert evaluation. The professor and the assistant were members of the commission that evaluated the lesson by the "teacher". The "Observation of mathematics lessons" conducted by the "teacher" was evaluated according to 5 criteria. The score for each criterion ranged from 1 to 3 points. The evaluation system is presented in Table 1 .

Table 1 "Teacher" Assessment Questionnaire

\begin{tabular}{|c|l|c|}
\hline № & \multicolumn{1}{|c|}{ Criteria } & Points (1-3) \\
\hline 1 & Lesson focus & \\
2 & Effective lesson planning & \\
3 & The mastery level of a teacher on the topical material & \\
4 & Interaction of the teacher with pupils & \\
5 & Using activation methods and techniques & \\
\hline \multicolumn{2}{|c|}{ Total: } & \\
\hline
\end{tabular}

- $\quad$ The survey. The survey was conducted twice before practice and after practice in high school. The questions of the questionnaire were answered both by the students who conducted the lesson and by the students who played the roles of teacher, pupils and the principal. Students answered 5 questions "Yes" or "No" about their impressions of the role-playing game results (Table 2).

Table 2 Survey Questionnaire

\begin{tabular}{|c|l|c|c|}
\hline № & \multicolumn{1}{|c|}{ Question } & Yes & No \\
\hline 1 & Did role-playing game pique your interest? & & \\
2 & Did the game arouse interest in the discipline "Methods of teaching & & \\
3 & mathematics" & Did the game simulates a real situation of observing mathematics lessons & \\
4 & Did this game develop professional skills of the teacher? & & \\
5 & Did this game give an opportunity to understand what problems the & & \\
& teacher faces? & & \\
\hline
\end{tabular}


Ivanova et al., 2021. Using Role-Playing Game for Professional Skills

Formation of Prospective Teachers

\section{The Results of the Experiment}

In order for the situations that arise in the lesson to be closer to reality and all participants to perform their roles well, the selection of students for these roles was carried out in accordance with the personality types of Myers-Briggs (MBTI). MBTI divides personality differences into four opposite pairs, whereby it is possible to allocate sixteen possible personality types. The sixteen types are usually designated by a four-letter abbreviation, the initial letters of each of their four preference types. For example: ENFJ: Extraversion (E), Intuition (N), Feeling (F), Judgment (J); ISTP: Introversion (I), Feeling (S), Thinking (T), Perception (P) (Rushton, Morgan \& Richard, 2007). Abbreviations apply to all sixteen types by analogy.

It is believed (Capretz, 2002) that the personality type ISTJ occurs most often, the second most common is ESTJ or INTP and INTJ. In the study (Rushton, Morgan \& Richard, 2007), it is showed that personality types: ISTJ (16.46\%), ESTJ (12.75\%), ENTJ (9.43\%), INTJ (9.43\%), INTP (8.46\%) and ENTP (7.43\%), most often found among students studying STEM disciplines. In total, personality types ISTJ, ESTJ, INTJ and INTP make up more than 50\% of the students among students of STEM specialties (Williamson, 2003). In the study (Howard, Culley \& Dekoninck, 2008) it is concluded that the most widespread personality type is ISTJ (16.9\%), and the second is INTJ (12.3\%), further ENTP (11.8\%); ESTJ (9.2\%), ISTP (7.7\%) and INTP (7.2\%). Thus, only four personality types ISTJs, INTJs, ENTPs and ESTJs make up 50.2\% of the total number of students. The data of another survey (Thomas, Benne, Marr, Thomas \& Hume, 2000) also found the prevalence of ISTJ (18.1\%), and the second place ESTJ (10.3\%), other personality types ranked in the following sequence: INTP (9.4\%), INTJ (8.5\%), ISTP (8.2\%). Personality types characteristic of prospective Math teachers are established in the paper (Ivanov, Dimitrov, Ivanova \& Olefir, 2019). Students with high academic achievement in mathematics usually have personality types: ISTJ, INTP, ESTJ, INTJ, ENTP, ENTJ и ISTP. The first three constructs, for example ENF or IST, are most significant for characterizing an individual (McCaulley, 2000).

H. J. Eysenck has noted that "child's personality determines to a large extent his or her reaction to specific methods of teaching, and even to the whole ethos and atmosphere of the teaching situation" (Eysenck, 1996). P. Hedges pointed out that "a mismatch between teacher and pupil temperament will exist, with potentially serious consequences" (Hedges, 1997). In view of the above, we believe that students with certain personal types should be selected for the roles of "bad and good pupils".

An extrovert student of personality types EST и ENT was chosen for the role of a «Good pupils». He had to give instant answers to problem without waiting 
for permission to answer and without explaining the course of the solution. The role of another "good pupils" was played by students with personality types IST and INT, who had to give the correct answers in the most detailed and timeconsuming manner. There were four "good pupils". Students from ESF, ISF, ENF, and INF were selected for the role of «bad pupils". ESF and ENF students acted as «bad pupils" who interfered with the lesson with cues and noise. ISF, INF students played the role of «bad pupils" who cannot understand explanations and require repeated repetition. The "principal" was selected from students with personality types IST, ISF and INT. His task was to behave incorrectly, to make comments to students and correct the teacher.

An experiment was carried out, the purpose of which is to establish differences in the game in the case when the personality types of participants are not taken into account and when selecting participants in accordance with their personality types.

The experiment was carried out for three years. It was attended by undergraduate students in the framework of the practice. Each year, it held six lessons - three lessons based on personality types and three without taking into account the personality types of participants. The data obtained in the case when the personality types of the participants are not taken into account are placed on a white background. The data received when the participants personality types are taken into account are located on a blue background. The results of the survey obtained before the practice in high school are presented in Table 3 and results of the survey after the practice in Table 4 . The arithmetic mean of the survey data before and after the practice is summarized in Table 5 .

The greatest number of positive answers was received on the third question. In the instance when students for roles were selected taking into account personality types, the imitation of the lesson was closer to real. It is important that this assessment was not downgraded after the students completed the teaching practice at school.

Table 3 The Result of the Survey before Practice

\begin{tabular}{|c|c|c|c|c|c|}
\hline $\begin{array}{l}\text { Time when Number of question } \\
\text { the survey was conducted }\end{array}$ & 1 & 2 & 3 & 4 & 5 \\
\hline 2018 & 72 & 64 & 75 & 68 & 79 \\
2018 & 81 & 67 & 81 & 84 & 87 \\
2019 & 68 & 64 & 84 & 74 & 88 \\
2019 & 84 & 81 & 82 & 80 & 84 \\
2020 & 74 & 69 & 80 & 70 & 88 \\
2020 & 76 & 72 & 84 & 79 & 88 \\
total result & 71,3 & 65,7 & 79,7 & 70,7 & 85,0 \\
total result & 80,3 & 73.3 & 82,3 & 81,0 & 86,3 \\
\hline
\end{tabular}


Ivanova et al., 2021. Using Role-Playing Game for Professional Skills

Formation of Prospective Teachers

Table 4 The Result of the Survey after Practice

\begin{tabular}{|c|c|c|c|c|c|}
\hline $\begin{array}{l}\text { Time when } \\
\text { the survey was conducted }\end{array}$ & 1 & 2 & 3 & 4 & 5 \\
\hline 2018 & 77 & 69 & 72 & 72 & 75 \\
2018 & 77 & 74 & 85 & 79 & 82 \\
2019 & 75 & 71 & 83 & 70 & 80 \\
2019 & 85 & 73 & 90 & 73 & 89 \\
2020 & 76 & 72 & 76 & 69 & 86 \\
2020 & 76 & 72 & 91 & 82 & 84 \\
\hline total result & 76,0 & 70,7 & 77,0 & 70,3 & 80,3 \\
total result & 79,3 & 73,0 & 88,7 & 78,0 & 85,0 \\
\hline
\end{tabular}

Table 5 Arithmetic Mean Result

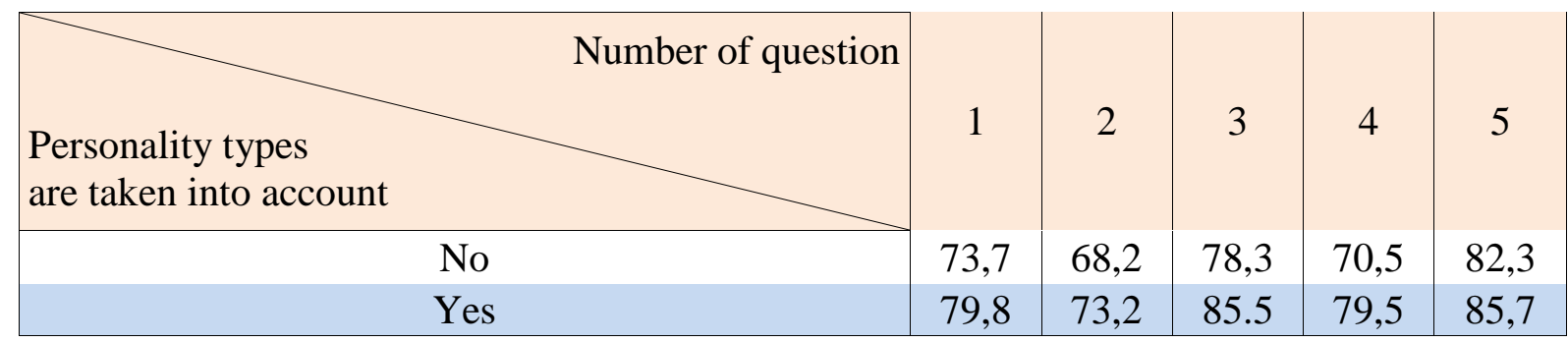

As can be seen from the results of the survey, $78.3 \%$ of respondents believe that the role-playing game "Observing Mathematics Lessons" allowed to better model the real situation in the lessons. When we organize and conduct the game take into account the personality types of the participants, this value increases to 85.5\%. The first hypothesis of the study was confirmed.

The students noted (70.5\%) that the experiment helps to develop professional skills. However, after the practice, the score was slightly reduced. If we take into account the personality types of the participants, this value increases to $79.5 \%$. The second hypothesis was also confirmed.

Analysis of the experiment results showed that the game form of the lesson aroused the interest of students. In the instance when students in the role are selected based on personality types, interest in the experiment was greater. The experiment also caused an increase in interest in the studied discipline. The interest in the experiment was more persistent and did not diminish after completing practice at school. The connection between the experiment and the discipline being studied is not so strong. After completing school practice, the percentage of students who noted an increase in interest in the discipline slightly decreased.

The students also noted that the experiment made it possible to understand what tasks the teacher faces. However, after the practice, the score was also 
slightly reduced. Moreover, for these two options for organizing the game, it was noted that the proposed variant of modelling a role-playing game is more effective.

As the experience of the experiment shows, accounting for the personality type of "principal" is not so important. Students who played the role of a "good pupils" noted that they realized that this pupil can also be a problem during the lesson. Students noted that they remembered their years of schooling and now understand that being "good pupils", reacting quickly to the teacher's problems, sometimes interferes with learning. Students noted that it is enough easy to portray a "bad pupil" who interferes with the lesson. The students came to the conclusion that the most difficult role is the "bad student", who tries to understand the material but cannot because of the inclination to study the humanities. The selection of students with the appropriate personality types for the role of "bad pupil" and "good pupil" made the "Observing Mathematics Lessons" more realistic and aroused the enthusiasm of the participants in the experiment. The experiment carried out organically fits into the teaching of the discipline "Methods of teaching mathematics». The time allotted for the discipline is barely enough to experiment with six lessons. Three classes were held in the framework of the training course, and the three classes, as agreed with the students, were held optional for those wishing to participate. To increase the relevance of the experiment, it would be desirable for all students in the academic group to act as "teachers". It would also be useful for preparing prospective math teachers. For this purpose, the number of hours for the discipline "Methods of teaching mathematics" should be increased.

\section{Conclusion}

Under the role-playing game, some researchers understand the use of school objects to teach counting skills or the use Massive Multiplayer game and Arcade game to increase interest in the studied discipline, as well as teaching computer characters created in the Second Life program. From our point of view, the roleplaying game is most effective when the roles are played by students. To organize the game, it is advisable to use the experience accumulated in management theory to take into account the personality characteristics of students in the form of team roles or personality types. The elements of the role-playing game are widely used in the preparation of prospective teachers in the form of a lesson or its fragment. The most successful interpretation of this game is when students play the roles of "bad" and "good" pupils, as well as the principal. This form of lesson simulation has been improved. Students with certain personality types were selected for the roles of "good" and "bad" pupils. The personality types of students are determined in accordance with the Myers Briggs methodology. Students with personality 
Ivanova et al., 2021. Using Role-Playing Game for Professional Skills

Formation of Prospective Teachers

types ESF and ENF were selected for the role of "bad" pupils who interfered with the lesson, and personal types ISF, INF played the role of pupils who cannot understand the explanations. For the role of "good" pupils, were chosen extroverts EST and ENT, who gave instant answers to the problem, and introverts IST and INT, who gave overly detailed explanations of the solution. It was found that this form of imitation of an "Observing Mathematics Lessons" aroused interest among students; when selecting students with certain personality types, interest was greater. A survey conducted among students showed that the majority of students believe that this game simulates the real situation of an observing lesson - 78.3\%. In the case of the selection of students with certain personality types, the percentage of students holding this opinion is more than $85.5 \%$. Students see the advantage of the proposed "Observing Mathematics Lessons" imitation primarily in the formation of professional skills $70.5 \%$, in the case when personality types are taken into account, the percentage rises to $79.5 \%$.

\section{Acknowledgments}

This work has been accomplished with financial support by the Grant No BG05M2OP001-1.002-0011 "MIRACle (Mechatronics, Innovation, Robotics, Automation, Clean technologies)", financed by the Science and Education for Smart Growth Operational Program (2014-2020) and co-financed by the European Union through the European structural and Investment funds.

\section{References}

Ahmad, W. F., Shafie, A. B., \& Latif, M. H. (2010). Role-playing game-based learning in mathematics. Electronic Journal of Mathematics \& Technology, 4(2), 184-196. Retrieved from https://www.semanticscholar.org/paper/Role-Playing-Game-Based-Learning-inMathematics-Ahmad-Shafie/e57030c765231433ebe820b6518286e33cb193c6?p2df

Anagnostopoulou, E., \& Olivotos, I. (2019). The Red Circle project: How mathematics can be embedded in online gaming quests for enhancing learning and teaching. Retrieved from https://alm-online.net/wp-content/uploads/2019/10/Anagnostopoulou-and-Olivotos.pdf

Capretz, L. F. (2002). Is there an engineering type. World Transactions on Engineering and Technology Education, 1(2), 169-172.

Capraro, R. M., \& Capraro, M. M. (2002). Myers-briggs type indicator score reliability across: Studies a meta-analytic reliability generalization study. Educational and Psychological Measurement, 62(4), 590-602.

Chryssolouris, G., Mourtzis, D., Stavropoulos, P., Mavrikios, D., \& Pandremenos, J. (2008). Knowledge management in a virtual lab collaborative training project: a mini-formula student car design. In Methods and Tools for Effective Knowledge Life-CycleManagement, 435-446. Retrieved from https://eric.ed.gov/?id=EJ1191707

Crow, M. L., \& Nelson, L. P. (2015). The effects of using academic role-playing in a teacher education service-learning course. International Journal of Role Playing, 5. Retrieved 
from http://ijrp.subcultures.nl/wp-content/uploads/2016/12/IJRP-5-Crow-andNelson.pdf

Dewey, J. (1927). The public and its problems. Chicago: Swallow Press.

Eysenck, H. J. (1996). Personality and the experimental study of education. European Journal of Personality, 10(5), 427-439 https://doi.org/10.1002/(SICI)1099-0984(199612) 10:5<427::AID-PER254>3.0.CO;2-H.

Fito-Bertran, A., Hernandez-Lara, A. B., \& Serradell-Lopez, E. (2014). Comparing student competences in a face-to-face and online business game. Computers in Human Behavior, 30, 452-459. https://doi.org/10.1016/j.chb.2013.06.023

Hedges, P. (1997). Personality discovery: Personality patterns in teachers and their pupils. Pastoral Care in Education, 15(3), 17-22. https://doi.org/10.1111/1468-0122.00061

Howard, T. J., Culley, S. J., \& Dekoninck, E. (2008). Describing the creative design process by the integration of engineering design and cognitive psychology literature. Design Studies, 29(2), 160-180. https://doi.org/10.1016/j.destud.2008.01.001

Ivanova, S., Dimitrov, L., Ivanov, V., \& Naleva, G. (2019). An Experiment on the Joint use of the Heuristic and Project Methods at the University. In 2019 II International Conference on High Technology for Sustainable Development (HiTech),1-5. IEEE. https:// doi: 10.1109/HiTech48507.2019.9128248.

Ivanov, V., Dimitrov, L., Ivanova, S., \& Olefir, O. (2019). Creativity enhancement method for STEM education. In 2019 II International Conference on High Technology for Sustainable Development (HiTech),1-5. IEEE. https://doi: 10.1109/HiTech48507.2019. 9128255

Jarvis, L., Odell, K., \& Troiano, M. (2002). Role-playing as a teaching strategy. Strategies for application and presentation, staff development and presentation. Retrieved from https://citeseerx.ist.psu.edu/viewdoc/download?doi=10.1.1.550.2518\&rep=rep1\&type= pdf

Johnson, E. B. (2002). Contextual teaching and learning: What it is and why it's here to stay. Corwin Press.

Kilgour, P., Reynaud, D., Northcote, M. T., \& Shields, M. (2015). Role-playing as a tool to facilitate learning, self-reflection and social awareness in teacher education. International Journal of Innovative Interdisciplinary Research, 2(4), 8-20. Retrieved from https://research.avondale.edu.au/edu_papers/73/

Lui, R., \& Au, C. H. (2020). IS educational game: Adoption in teaching search engine optimization (SEO). Journal of Computer Information Systems, 60(3), 233-243. https://doi.org/10.1080/08874417.2018.1461034

Ma, T., Brown, I. A., Kulm, G., Davis, T. J., Lewis, C. W., \& Allen, G. D. (2016). Constructing and role-playing student avatars in a simulation of teaching algebra for diverse learners. Urban Education, 51(5), 534-555. https://doi.org/10.1177\%2F00420859 14542658

Mahon, J., Bryant, B., Brown, B., \& Kim, M. (2010). Using second life to enhance classroom management practice in teacher education. Educational Media International, 47(2), 121134. https://doi.org/10.1080/09523987.2010.492677

McCaulley, M. H. (2000). Myers-Briggs Type Indicator: A bridge between counseling and consulting. Consulting Psychology Journal: Practice and Research,52(2), 117. https://doi.org/10.1037/1061-4087.52.2.117

Rushton, S., Morgan, J., \& Richard, M. (2007). Teacher's Myers-Briggs personality profiles: Identifying effective teacher personality traits. Teaching and Teacher Education, 23(4), 432-441. https://doi.org/10.1016/j.tate.2006.12.011 
Ivanova et al., 2021. Using Role-Playing Game for Professional Skills

Formation of Prospective Teachers

Schmidt, M. (2010). Learning from teaching experience: Dewey's theory and preservice teachers' learning. Journal of research in music education, 58(2), 131-146.

Shafie, A., \& Fatimah, W. (2011). Design of the learning module for math quest: a role playing game for learning numbers. In International conference on communication engineering and networks IPCSIT, Vol. 19, 107-113. Retrieved from https://www.researchgate.net/ profile/Wan-Fatimah-Wan-

Ahmad/publication/267861098_Design_of_the_Learning_Module_for_Math_Quest_A _Role_Playing_Game_for_Learning_Numbers/links/553dbceb0cf29b5ee4bcde6d/Desig n-of-the-Learning-Module-for-Math-Quest-A-Role-Playing-Game-for-LearningNumbers.pdf

Thomas, A., Benne, M. R., Marr, M. J., Thomas, E. W., \& Hume, R. M. (2000). The evidence remains stable: The MBTI predicts attraction and attrition in an engineering program. Journal of Psychological Type, 55, 35-42.

Vanovskiy, V. (2014). International Physicists' Tournament - the team competition in physics for university students. European Journal of Physics, 35(6), 064003. https://doi.org/ 10.1088/0143-0807/35/6/064003

Verbickij, A. A., \& Larionova, O. G. (2009). Lichnostnyj i kompetentnostnyj podhody $v$ obrazovanii: problemy integracii. Izdatel'skaja gruppa Logos.

Williamson, J. (2003). Suiting library instruction to the Myers-Briggs personality types and Holland Vocational personality types of engineering students. Issues in Science and Technology Librarianship, 37(2). https://doi.org/10.5062/F4154F1G 